\title{
REKOMENDASI PEMUPUKAN FOSFOR (P) PADA PERTANAMAN J AGUNG BERDASARKAN STATUS P TANAH DI KECAMATAN KINALI, LUHAK NAN DUO DI KABUPATEN PASAMAN BARAT
}

Yulinar Zubaidah

BPTP Sukarami Solok

\begin{abstract}
A study of $\mathrm{P}$ - nutrient status ( $\mathrm{P}$ - soil) in the maize production central in Kinali, Luhak Nan Duo in Pasaman, Sub Regency Pasaman Barat to find of the recommendation of phosphorous (P) fertilization. A study is conducted from October to December 2005. Method of research by crossed land area and took soil sampling with composite. Each soil sampling represented of land area research $50-80$ ha with $0-20 \mathrm{~cm}$ dept for land area 7702,2 ha and 97 soil sample and then analyzed by Bray II methods. From 7702,2 ha of land area were survey founded P high content 5351,5 ha $(69,4 \%), \mathrm{P}$ - with middle content 1487,5 ha $(19,3 \%)$ and $\mathrm{P}-$ lower content 863,2 ha $(11,2 \%)$. Based on soil $\mathrm{P}$ - status, $\mathrm{P}$ nutrient requirement to 90,250 and $500 \mathrm{~kg}$ SP 36 respectively and yield prospecting 4,5 ton/ha with $14 \%$ water content equal to 8 ton dry grain seed at harvesting with water content $25 \%$.
\end{abstract}

\section{Key Words: P-fertilizer, F ertilization Recommendation, Soil P-status}

Pendahuluan

Perancangan program swasembada jagung tahun 2006 di Sumatra Barat dengan sasaran produksi sebesar 171,312 ton dengan Produktifitas 6 ton pipilan kering/Ha. (diperta motri; 2004). Sasaran utama adalah untuk memenuhi kebutuhan jagang sebagai pekan ternak. Tahun 2004 saja kebutuhan jagung untuk pekan ternak mencapai 115,675 ton, sedangkan produksi jagung tahun 2004 baru mencapai 99,336 ton. Sumatra Barat masih kekurangan jagung untuk pekan ternak sebesar 164,339 ton. Daerah yang berpotensi untuk perkembangan jagung tahun 2006 telah ditetapkan oleh Pemda Sumbar yaitu Pasaman Barat dengan areal 13,175 Ha dan kabupaten Pasisir Selatan seluas 13,000 Ha.

Untuk itu Pemda Pasaman Barat c/q Dinas Pertanian dan Pertenakan Pasaman Barat berinisiatif mensurvei lahan jagung yang ada disentra produksi jagung, terutama unsur fosfor (P). Hasil rata-rata jagug per $\mathrm{Ha}$ di Pasaman Barat sejak tahun 1999 s/d 2004 berturut turut 5,37 ton; 4,81 ton; 5,03 ton; 5,58 ton dan 5,35 ton (Bapeda TK2 pasaman 1999 s/d 2003 dan bapeda pasaman barat
2003 dan 2004 ). Dari data ini terlihat bahwa produksi sudah cendrung stabil, karena tidak ada lagi peningkatan atau penurunan hasil yang disiknifikasikan. Dari hasil survey tersebut diharapkan didapatkan kebutuhan pupuk faspor $(\mathrm{P})$ yangtepat untuk meningkat kan hasil produksi diatas rata-rata sekarang.

Produksi tanaman pada umum nya ditentukan oleh dua faktor yaitu luas panen dan produktifitas tanaman itu sendiri. Peningkatan produksi harus bertitik tolak dari kedua faktor tersebut (Puslitbangtan 2002) bila perluasan areal menjadi kendala. Peningkatan produksi dapat dicapai dengan peningkatan produktifitas tanaman itu sendiri dengan cara meningkatkan kesuburan tanah, melalui pemupukan, memakai varietas unggul, pengairan dan lain - lainnya.

Turunnya hasil antara lain disebabkan sudah menurun nya tingkat kesuburan tanah. Untuk itu diperlukan peningkatan pembenihan pupuk. Pupuk fafor $(\mathrm{P})$ hanya $30 \%$ yang dapat diserap oleh tanaman dari jumlah yang diberikan (Hong, 1968 dan Harjowigeno, 2003). Hal ini disebab kan karena pupuk $\mathrm{P}$ sulit tersedia didalam tanah. Ketersediaan fosfor $(\mathrm{P})$ sangat 
Tabel. 1 Jumlah contoh tanah pada masing-masing Daerah Survai Kabupaten Pasaman Barat.

\begin{tabular}{llcc}
\hline No & Kecamatan & $\begin{array}{c}\text { Luas daerah survei } \\
(\mathrm{Ha})\end{array}$ & $\begin{array}{c}\text { Jumlah Contoh } \\
\text { Tanah }\end{array}$ \\
\hline 1 & Pasaman & 963,1 & 26 \\
2 & Luhak nan duo & 1736,4 & 36 \\
3 & Kinali & 5002,7 & 35 \\
\hline & Jumlah & 7702,2 & 97 \\
\hline
\end{tabular}

dipengaruhi oleh $\mathrm{PH}$ tanah. $\mathrm{Al}, \mathrm{Fe}, \mathrm{Mn}$ sehingga P-tersedia bisa berobah menjadi Ptidak tersedia. Pada tanah Andisol (abu vulkan). Fosfor yang berada dalam bentuk P-retensi juga tidak dapat dimanfaatkan oleh tanaman.

Penelitian ini bertujuan untuk menentukan status unsur fosfor $(\mathrm{P})$ dalam tanah serta penyebarannya di daerah pertanaman jagung di Kecamatan Pasaman, Luhak Nan Duo dan Kinali Kabupaten Pasaman Barat serta untuk menentukan rekomendasi pupuk fasfor (P) untuk tanaman jagung berdasarkan status hara Ptanah

Bahan dan Metoda

Pengkajian diadakan di tiga Kecamatan di Kabupaten Pasaman Barat yaitu Kecamatan Pasaman, Luhak Nan Duo dan Kecamatan Kinali dari bulan Oktober sampai Desember 2005.

Metode pengkajian adalah survai dengan metoda penjelajahan seluruh daerah survei melalui rintisan (jalur pengamatan). Pada hamparan yang luas pengambilan contoh tanah di atur melalui jalur - jalur melalui jarak $500-1000$ m. Titik pengambilan contoh tanah tiap $500 \mathrm{~m}$ dengan jarak jalur $1000 \mathrm{~m}$, sehingga satu (1) titik pengamatan koordinat dan jarak titik pengambilan contoh tanah dipakai alat GPS (global position system).

Pengambilan contoh tanah dilapangan dengan memakai metada Bulk komposit.

diambil oleh tanaman (lebih kurang 20\%) walaupun kebutuhan tanaman terhadap $\mathrm{P}$ tinggi. Sisa nya akan tetap berada dalam tanah (40 bang hong). contoh tanah di ambil pada lapisan topsoil kedalaman 0-20 cm. Beberapa contoh tanah indifidu digabung, diaduk sampai homogen dan diambil kira-kira $1 / 2 \mathrm{~kg}$ untuk analisis unsur fosfor (P). Satu contoh tanah mewakili daerah survai seluas $50 \mathrm{Ha}$. Tingkat survai tanah adalah semi detail. Peta dasar yang di gunakan adalah peta topografi skala 1: 50.000 .

\section{Hasil dan Pembahasan}

Berdasarkan hasil analisis laboratorium dan kemudian diolah dengan kriteria yang disusun oleh balai pusat penelitian tanah bogor (cit Hardjowigeno, 2003) didaerah survei dijumpai unsur fosfor (P) dari tinggi sampai rendah dengan kendungan $\mathrm{P}$ berkisar diri 6,0 ppm sampai $11,4 \mathrm{ppm}$.

$\mathrm{P}_{2} \mathrm{O}_{5}$ tinggi dijumpai di ketiga kecamatan yang disurvei dan yang terluas dijumpai di kecamatan Kinali dengan total luas $2891,2 \mathrm{Ha}$ atau $37,5 \%$ dari total luas daerah yamg disurvai dan sedikit dijumpai dikecamatan Pasaman dengan total luas $778,8 \mathrm{Ha}$ atau $10,1 \%$ dari total luas daerah survai. Tingginya kandungan hara $\mathrm{P}$ dikecamatan Kinali ini diduga karena pemberian pupuk $\mathrm{P}$ yang intensif selama pertanaman jagung, pengaruh bahan induk tanah yang berasal dari kipasan abu vulkanik dan tambahan bahan yang terangkut dari bahan Batang Mandiangin, Masang Godang dan Batang Kinali. Disamping itu unsur P merupakan unsur yang sedikit

Kandungan $\mathrm{P}_{2} \mathrm{O}_{5}$ tinggi dijumpai di ketiga kecamatan yang disurvei dan yang terluas dijumpai di kecamatan Kinali dengan total luas $2891,2 \mathrm{Ha}$ atau $37,5 \%$ dari total 
luas daerah yamg disurvai dan sedikit dijumpai dikecamatan Pasaman dengan total luas $778,8 \mathrm{Ha}$ atau $10,1 \%$ dari total luas daerah survai. Tingginya kandungan hara $\mathrm{P}$ dikecamatan Kinali ini diduga karena pemberian pupuk $\mathrm{P}$ yang intensif selama pertanaman jagung, pengaruh bahan induk tanah yang berasal dari kipasan abu vulkanik dan tambahan bahan yang terangkut dari bahan Batang Mandiangin, Masang Godang dan Batang Kinali. Disamping itu unsur P merupakan unsur yang sedikit diambil oleh tanaman (lebih kurang 20\%) walaupun kebutuhan tanaman terhadap P tinggi. Sisa nya akan tetap berada dalam tanah (40 bang hong).

Tabel 2. Sebaran Status Fospor (P) di Kecamatan Pasaman Luhak nan Duo dan kinali, Kabupaten Pasaman Barat

\begin{tabular}{|c|c|c|c|}
\hline No & Status fosfor(P) & Kecamatan & Kenagarian/jorong \\
\hline 1 & Tinggi & $\begin{array}{l}\text { Pasaman } \\
\text { Luhak nan duo }\end{array}$ & $\begin{array}{l}\text { Sukamenanti } \\
\text { Cubadak } \\
\text { Koto Aur } \\
\text { Lubuk Gadang } \\
\text { Sariak } \\
\text { Mahakarya } \\
\text { S Talang } \\
\text { Padang Panjang } \\
\text { Malasiro } \\
\text { Sumbu Agung } \\
\text { Padang Jirak } \\
\text { Bancah Uban } \\
\text { VI Selatan } \\
\text { Lagam } \\
\text { Alamanda } \\
\text { Wonosari } \\
\text { Muaro Bingung } \\
\text { VI Koto Saiyo } \\
\text { Kola }\end{array}$ \\
\hline 2 & Sedang & $\begin{array}{l}\text { Pasaman } \\
\text { Luhak Nan Duo } \\
\text { Kinali }\end{array}$ & $\begin{array}{l}\text { Sukamenanti } \\
\text { Togar } \\
\text { Durian } \\
\text { Suka makmur } \\
\text { Sidodadi } \\
\text { Kola }\end{array}$ \\
\hline 3 & Rendah & $\begin{array}{l}\text { Pasaman } \\
\text { Luhak nan Duo } \\
\text { Kinali }\end{array}$ & $\begin{array}{l}- \\
\text { Sidodadi }\end{array}$ \\
\hline
\end{tabular}

Daerah yang mempunyai kandungan P-sedang meliputi luas $1487,5 \mathrm{Ha}$ atau $19,3 \%$ dari total luas daerah survei. Terluas terdapat di daerah Kinali yaitu 1248,3 Ha (lebih kurang 15,2\%). Terutama terluas didaerah Sidodadi dan Kola. Daerah dengan kandungan $\mathrm{P}$ rendah mencakup luas 863,2 $\mathrm{Ha}$ atau $11,2 \%$ dari luas daerah survai, daerah dengan kandungan $\mathrm{P}$ rendah ini terdapat di kecamatan kinali yaitu di daerah sidodadi. Rendahnya kandungan P didaerah ini diduga karena daerah merupakan daerah 
cekungan dan bahan induk tanah lebih didominasi oleh bahan organik (gambut). Gambut mempunyai $\mathrm{pH}$ tanah rendah $(3,0$ $4,5)$ ketersediaan unsur N, P, K rendah serta miskin mineral (Radja Gukguk ,1989).

Kebutuhan pupuk SP 36, dihitung berdasarkan atas interprestasi produksi 4,5 ton pipilan kering panen (k.a14 \%) dan setara dengan 8,0 ton pipilan panen (k.a 25 $\%)$ dan lahan dengan status $\mathrm{P}$ tinggi, dibutuhkan pupuk SP $3690 \mathrm{~kg} / \mathrm{ha}$. Tersebar didaerah Sukamenanti, ,Koto Aur, Cubadak (Kecamatan Pasaman), Padang Panjang, Malasiro, Sungai Talang, Sariak, Batang Kapa (Kacamatan Luhak Nan Duo) dan Sumber Agung, Wanosari, Bancah Uban, Padadang Jirak, IV Koto Selatan, Alamanda, B. Koto Gadang, Sidodi (Kecamatan Kinali). Untuk $\mathrm{P}$ dengan status sedang dibutuhkan pupuk SP36 250kg/Ha yang tersebar didaerah sidodadi, B Koto Gadang (Kecamatan Kinali), Suka Makmur (Kecamatan Luhak Nan Duo) dan Sukamenanti, dan Durian (Kecamatan Pasaman). Dengan status rendah membutuhkan pupuk SP $36500 \mathrm{Kg} / \mathrm{Ha}$, hanya terdapat didaerah Sidodi Kecamatan Kinali.

Lahan - lahan dengan status $P$ tinggi.bukan berarti tidak dibutuhkan lagi pupuk P. Hal ini disebabkan karena tanaman jagung merupakan tanaman yang rakus terhadap hara fasfor $(\mathrm{P})$. Bila terjadi sedikit saja kekurangan $\mathrm{P}$ dalam tanah maka tanah akan memperlihatkan gejala defisiensi $\mathrm{P}$ yang di tunjukan dengan daun kerdil, tulang daun bewarna ungu (Poerwidodo, 1992).

Table 3. Status Unsur Hara Fosfor (P) di kecamatan Pasaman Barat Luhak Nan Duo dan Kinali

\begin{tabular}{|c|c|c|c|c|}
\hline \multirow[t]{2}{*}{ No } & \multirow[t]{2}{*}{ Status Hara } & \multirow[t]{2}{*}{ Kecamatan } & \multicolumn{2}{|c|}{ Luas } \\
\hline & & & $\mathrm{Ha}$ & $\%$ \\
\hline \multirow{4}{*}{1} & \multirow{4}{*}{ Tinggi } & Pasaman & 778,8 & 10,1 \\
\hline & & Luhak nan Duo & 1681,5 & 21,8 \\
\hline & & Kinali & 2891,2 & 37,5 \\
\hline & & jumlah & 5351,5 & 69,4 \\
\hline \multirow{4}{*}{2} & \multirow{4}{*}{ Sedang } & Pasaman & 184,3 & 2,4 \\
\hline & & Luhak non Duo & 54,9 & 0,7 \\
\hline & & Kinali & 1248,3 & 16,2 \\
\hline & & jumlah & 1487,5 & 19,3 \\
\hline \multirow{4}{*}{3} & \multirow{4}{*}{ Rendah } & Pasaman & 0,0 & 0,0 \\
\hline & & Luhak nan Duo & 0,0 & 0,0 \\
\hline & & Kinali & 863,2 & 11,2 \\
\hline & & Jumlah & 863,2 & 11,2 \\
\hline & Total & & 7702,2 & 100,0 \\
\hline
\end{tabular}


Tabel 4. Rekumendasi Pupuk P (SP36) untuk Tanaman Jagung Berdasarkan Status P- Tanah di Kecamatan Pasaman, Luhak Nan Duo, Kinali, Kabupaten Pasaman Barat

\begin{tabular}{|c|c|c|c|c|c|}
\hline \multirow[b]{2}{*}{ No } & \multirow[b]{2}{*}{ Status P } & \multirow[b]{2}{*}{ Kecamatan } & \multirow{2}{*}{$\begin{array}{c}\text { Kebutuhan Pupuk SP } \\
36 \mathrm{~kg} / \mathrm{Ha}\end{array}$} & \multicolumn{2}{|c|}{ Luas } \\
\hline & & & & $\mathrm{Ha}$ & $\%$ \\
\hline \multirow[t]{3}{*}{1} & P tinggi & Pasaman & 40 & 778,8 & 10,1 \\
\hline & & Luhak Nan Duo & & 1681,5 & 21,8 \\
\hline & & Kinali & & 2891,2 & 37,5 \\
\hline \multirow[t]{3}{*}{2} & $\mathrm{P}$ sedang & Pasaman & 250 & 184,3 & 2,4 \\
\hline & & Luhak nan Duo & & 54,9 & 0,7 \\
\hline & & Kinali & & 1248,3 & 16,2 \\
\hline \multirow[t]{3}{*}{3} & P rendah & Pasman & 500 & 0,0 & 0,0 \\
\hline & & Luhak nan Duo & & 863,2 & 0,0 \\
\hline & & Kinali & & 0,0 & 11,2 \\
\hline
\end{tabular}

P tinggi didalam tanah tidak banyak diserap oleh tanaman, karena penyerapan $\mathrm{P}$ sangat tergantung kepada $\mathrm{pH}$ tanah, KTK, kandungan bahan organik dan untuk tanah Andosol didapatkan $\mathrm{P}$ - retensi yaitu $\mathrm{P}$ yang tersekap pada permukaan mineral Alufian, sehingga tidak dapat diambil oleh tanaman (Hardjowigeno, 2003; Forth, 1988; Novizon, 2002 dan Tan, 1991). Untuk itu harus ada perlakuan agar $\mathrm{P}$ teretensi dibebaskan sehingga dapat diambil oleh tanaman seperti pemberian kapur bahan organic lain. Untuk lahan-lahan dengan kadar $\mathrm{P}$ tanah sedang dan rendah kebutuhan pupuk SP 36 dapat dikurangi dengan meningkatkan $\mathrm{pH}$ tanah, KTK dan bahan organanik tanah. Ini dapat dilakukan dengan pemberian bahan-bahan ameliorasi seperti penambahan kapur dan bahan organik (pupuk organik).

Kesimpulan

Hasil pengkajian rekumendasi pemupukan fasfor $(\mathrm{P})$ berdasarkan status $\mathrm{P}$ tanah di Kecamatan Kinali, Luhak nan Duo dan Pasaman, Kabupaten Pasaman Barat dapat disimpulkan beberapa hal :

1 Dari 7702,2 Ha daerah yang disurvai, ternyata lahan dengan kadar P tinggi 5351,5 Ha (69,4\%), $\mathrm{P}$ sedang $1487,5 \mathrm{Ha}(14,3 \%)$ dan $\mathrm{P}$ rendah $863,2 \mathrm{Ha}(11,2 \%)$
2 Kebutuhan pupuk SP36 pada lahan dengan kadar P-tinggi $90 \mathrm{~kg} / \mathrm{Ha}, \mathrm{P}-$ sedang $250 \mathrm{~kg} / \mathrm{Ha}$, dan P-rendah $500 \mathrm{~kg} / \mathrm{Ha}$.

3 Rekomendasi pemupukan $\mathrm{P}$ ini didasarkan atas status $\mathrm{P}$ tanah dan hasil akan dicapai sebanyak 4,5 ton pipilan kering (14\%) yang setara dengan 8 ton pipilan kering panen (KA 25\%)

4 Untuk mendapatkan rekomendasi pemupukan $\mathrm{P}$ (SP-36) yang tepat perlu dilakukan / atau dilanjutkan dilapangan dalam bentuk demplot dan analisis tanaman.

Pustaka

Bappeda Tingkat II Pasaman, 1999. Pasaman Dalam Angka. Kerjasama Bappeda Tk II Pasaman dan Kantor Statistik Kabupaten Pasaman $-, 2000$.

Pasaman Dalam Angka. Kerjasama Bappeda Tk II Pasaman dan Kantor Statistik Kabupaten Pasaman $-, 2001$.

Pasaman Dalam Angka. Kerjasama Bappeda Tk II Pasaman dan Kantor Statistik Kabupaten Pasaman $-2002$.

Pasaman Dalam Angka. Kerjasama Bappeda Tk II Pasaman dan Kantor Statistik Kabupaten Pasaman 
2003.

Pasaman Dalam Angka. Kerjasama Bappeda Tk II Pasaman dan Kantor Statistik Kabupaten Pasaman.

Bappeda Tingkat II Pasaman Barat,2003. Pasaman Barat Dalam Angka. Kerjasama Bappeda Tk II Pasaman Barat dan Kantor Statistik Pasaman Barat

Pasaman Barat dalam angka .kerja sama Bappeda Pasaman Barat dan Kantor Statistik Kabupaten Pasaman Barat

Bostang Radja Gukguk dan Bambang Setiadi, 1989. Strategi Pemanfaatan Gambut di Indonesia Kasus Pertanian. Prosiding Seminar Tanah Gambut untuk Perluasan Pertanian. Fakutas Pertanian Islam Sumatera Utara Medan.

Dinas Pertanian dan Holtikultura Propinsi Sumatera Barat, 2004. Program Pengembangan Swasembada Jagung di Propinsi Sumatera Barat

Forth, 1988. Dasar - dasar Ilmu Tanah. Diterjemahkan oleh Endang Dwi
Purbawati; Dwi Retno Lukiwati; Rahayuning Tri Mulatsih dan Editor; Sri Andani B Hudotono. Fakultas Pertenakan Universitas Diponegoro. Gajah Mada University Press. 782 hlm

Hardjowigeno, Sarwono, 2003. Ilmu Tanah. Akademika Pessindo Jakarta

Novizan, 2002. Petunjuk Pemupukan Efektif. Agro Media Pustaka

Poerwowidodo, 1992. Telaah Kesuburan Tanah. PT Angkasa Bandung, 275 hlm

Puslitbangtan, 2002. Inovasi Teknologi Jagung. Menjawab Tantangan Ketahanan Pangan Nasional. Puslitbangtan Bogor

Tan, K.H, 1991. Dasar - dasar Kimia Tanah. Penerjemah Ir. Didiek Hadjar Goenadi, M.Sc. Phd. Balai Penelitian Perkebunan Bogor. Penyunting Ir Bustang Radja Gukguk, M.Sc P.hd. fakultas Pertanian Universitas Gajah Mada. Gajah Mada University Press. $295 \mathrm{hlm}$ 